\title{
Specialty clothing: need of the day
}

\section{Introduction}

Specialty clothing is a relatively new and exciting segment of functional clothing. It is designed to offer suitable functionality, protection and comfort to the user, under defined condition of use. Unlike fashion clothing which is designer's creative instinct, the design and development of specialty apparels starts and finish with user's specific requirements. Manufacturing of readymade fashion clothing is based on standard body measurements with fashion designer's imaginative predilection for chunk of the young population. People like one hand disability, two leg disabilities, and limb disability demand specialty apparels for day to day life. But unfortunately, readymade garments for elderly and disabled people are not available in retail stores as they are not mass produced.

Clothing is one of the basic needs of human life, which is equally true in case of physically challenged people. People living with disabilities are referred to as the world's largest minority population. Specialty clothing can offer them an easy, time saving and pain free way of dressing. Design and engineering of specialty clothing is a challenging process. Depending on the type of use, the requirements from functional clothing may vary. For example, people with highly sensitive skin, we have to avoid clothing with hard seams. For wheel chair users and for persons lying prolonged time in bed, who have a relatively low heat production, the thermal comfort properties are required to be considered. In addition, the transmission of moisture (sweat) from the skin is also a frequent problem, which needs to be tackled in specialty garments Therefore; the design process of specialty garments begins by understanding various requirements of end user.

In last few years, many efforts have been taken place to design apparels for wheelchair users and for people with limb disabilities. But, till date, the problems of design \& development of specialty garments for people suffering from hand disability, leg disability, paralysis, mental disability, bent backbone, stiff \& rigid bone joints, twisted \& crooked joints, etc. has never been studied.

Out of the total population, $3 \%$ are disabled or handicapped, out of which, about a quarter of a million patients are in hospitals or homes whose stay is likely to be permanent or extended over a period of years; more than half are mentally challenged. The people including those who are mentally subnormal may also surfer physical disabilities and third are patients in elderly, while the others have been defined as 'young chronic sick'. Suitable clothing can improve the patient's appearance and make him appear more like a fit member of the community, as well as give greater comfort and easier dressing. Comfort and easy dress in and removal are the two factors which preserve the patient from physical aching and may save many hours of time for those caring for him. The choice of fabrics for different disabilities is directed by factors like frequency of washing. Some of the man-made fibers, including nylon, are not able to inhibit the development of unpleasant odors on the garments even when they are correctly laundered. These would not be suitable for disabilities such as tetraplegia, where unnecessary perspiration is often a problem. In such cases cotton, wool and cellulosic fibers may be the answer.

The variety of needs and requirements of all disabled people is too
Volume 3 Issue 3 - 2017

\author{
VK Dhange \\ DKTES's Textile \& Engineering Institute, Ichalkaranji, India
}

Correspondence: VK Dhange, DKTES's Textile \& Engineering Institute, Ichalkaranji, India, Tel 9975222635 ,

Email vkddkte@gmail.com

Received: November 20, 2017 | Published: November 29, 2017

great and most people whatever their disability, would prefer to buy their clothing in the same shop as their contemporaries. Different kind of specialty garments is required to be made available for disabled person such as leg protectors, cape, coat with the concealed apron, apron belt, integral gloves, etc. For persons lying prolonged time in bed, who have a relatively low heat production, the thermal comfort properties are important. Also the mechanical durability of the materials in certain parts of the products can be a problem in many cases. Textile products are also used in a more technical context for the wheelchair users are fairly well served with special garments of disabled patients. The individual requirements of disabled people regarding textiles and clothing are very much more diverse than for people without disabilities. The risk of fracture in the area of the hip is a particular problem for elderly people. It has been proved that hip protectors, which are inserted into pockets over this area of specially designed underpants, significantly reduce the number of hip fractures. As the fractures causes a person long suffering and the community high costs in terms of healthcare, both health and economic savings can be achieved by using the hip protectors.

People consider many things when choosing clothes. Today there is no longer correct fashion but for each individual the combination of fabric, fastenings, fit, style, color, design and price must be right. There is widely held belief that people with disabilities need special cloths. However, for disabled person it is very important that fabric, style and fit of the garment should be chosen very correctly and produced with right combination. It is advised that most of the people with disability can find clothes which are easy to put on and in which they both look and feel good and are fashionable. Many people have distorted image of their physical size and shape. Disabled people are no exception as such. It is important that the person with disabilities have the right size of garment for him or her according to their disability. The disability may result in weight loss or gain. It means that the individual may differ in size. It is difficult for disabled people to put-on the garments that are too big or too small. Any successful garment depends on using the right fabric. This is especially true for people with disabilities. The fabrics like Jersey knit and similar fabric which give and stretch make garment easier to put-on. Fabrics like soft woven materials, light weight fabrics made from cotton, acrylics, Viscose and blends like $\mathrm{p} / \mathrm{c} \& \mathrm{v} / \mathrm{c}$ as well as light weight wool should be chosen. The actual effects of disabilities can be minimized by a correctly chosen fabric. Disabled clothing requires frequent washing and tumble drying. The 
style of garment should be chosen by considering the disabilities of people. The fasteners like zip touch and close fasteners i.e. Velcro should be used.

People with limb disabilities have special needs for the aesthetic and functional structures of clothing, distinct from non-disabled people, and consequently their garments have specific design requirements. The final aim is to allow people with a disability a life of self-respect and facility. Here, combining the knowledge of human engineering (ergonomics) with textile materials and apparel technology, special modifications were designed in the garment to de-emphasize visual evidence of a person's disability, and strengthen function and convenience to meet the needs of body activities. Clothing for people with disabilities should satisfy standards such as putting on and off independently and conveniently. Clothing variation in body features while presenting no distinction from others; providing a physical and psychological sense of comfort and stability.

To conclude, specialty clothing gives a feeling of self-confidence and comfort to disabled wearer who feels physically, psychologically and socially at ease.

\section{Acknowledgements}

None.

\section{Conflict of interest}

Author declares there is no conflict of interest in publishing the article. 